University of Nebraska - Lincoln

DigitalCommons@University of Nebraska - Lincoln

\title{
Identification of the Ubiquitous Antioxidant Tripeptide Glutathione as a Fruit Fly Semiochemical
}

\author{
Xavier Cheseto \\ Jomo Kenyatta University of Agriculture and Technology \\ Donald L. Kachigamba \\ USDA-ARS \\ Sunday Ekesi \\ International Centre of Insect Physiology and Ecology \\ Mary Ndung'u \\ Jomo Kenyatta University of Agriculture and Technology \\ Peter E. A. Teal \\ USDA-ARS
}

See next page for additional authors

Follow this and additional works at: https://digitalcommons.unl.edu/usdaarsfacpub

Cheseto, Xavier; Kachigamba, Donald L.; Ekesi, Sunday; Ndung'u, Mary; Teal, Peter E. A.; Beck, John J.; and Torto, Baldwyn, "Identification of the Ubiquitous Antioxidant Tripeptide Glutathione as a Fruit Fly Semiochemical" (2017). Publications from USDA-ARS / UNL Faculty. 1769.

https://digitalcommons.unl.edu/usdaarsfacpub/1769

This Article is brought to you for free and open access by the U.S. Department of Agriculture: Agricultural Research Service, Lincoln, Nebraska at DigitalCommons@University of Nebraska - Lincoln. It has been accepted for inclusion in Publications from USDA-ARS / UNL Faculty by an authorized administrator of DigitalCommons@University of Nebraska - Lincoln. 


\section{Authors}

Xavier Cheseto, Donald L. Kachigamba, Sunday Ekesi, Mary Ndung'u, Peter E. A. Teal, John J. Beck, and Baldwyn Torto 


\section{Identification of the Ubiquitous Antioxidant Tripeptide Glutathione as a Fruit Fly Semiochemical}

Xavier Cheseto, ${ }^{\dagger, \ddagger}$ Donald L. Kachigamba, ${ }^{\S}$ Sunday Ekesi, ${ }^{\dagger}$ Mary Ndung ${ }^{\prime},{ }^{\ddagger}$ Peter E. A. Teal, ${ }^{\perp, \Phi}$ John J. Beck, ${ }^{\perp \odot}$ and Baldwyn Torto* ${ }^{* \dagger} \odot$

${ }^{\dagger}$ International Centre of Insect Physiology and Ecology (icipe), P.O. Box 30772-00100, Nairobi, Kenya

${ }^{\ddagger}$ Chemistry Department, Jomo Kenyatta University of Agriculture and Technology, P.O. Box 62000-00200 Nairobi, Kenya

${ }^{\S}$ Department of Agricultural Research Services, Bvumbwe Research Station, P.O. Box 5748, Limbe, Malawi

${ }^{\perp}$ Chemistry Research Unit, Center for Medical, Agricultural and Veterinary Entomology, Agricultural Research Service, U.S. Department of Agriculture, 1700 Southwest 23rd Drive, Gainesville, Florida 32608, United States

\section{Supporting Information}

ABSTRACT: Many insects mark their oviposition sites with a host marking pheromone (HMP) to deter other females from overexploiting these sites. Previous studies have identified and used HMPs to manage certain fruit fly species; however, few are known for African indigenous fruit flies. The HMP of the African fruit fly, Ceratitis cosyra, was identified as the ubiquitous plant and animal antioxidant tripeptide, glutathione (GSH). GSH was isolated from the aqueous extract of adult female fecal matter and characterized by LC-QTOF-MS. GSH level increased with increasing age of female fecal matter, with highest concentration detected from 2-week-old adult females. Additionally, GSH levels were 5-10-times higher in fecal matter than in the ovipositor or hemolymph extracts of females. In bioassays, synthetic GSH reduced oviposition responses in conspecifics of $C$. cosyra and the heterospecific species C. rosa, C. fasciventris, C. capitata, and Zeugodacus cucurbitae. These results represent the first report of a ubiquitous antioxidant as a semiochemical in insects and its potential use in fruit fly management.

KEYWORDS: Ceratitis cosyra, host marking pheromone, ovipositional deterrent, fruit fly

\section{INTRODUCTION}

Tephritid fruit flies are among the most notorious pests of horticultural crops worldwide with direct and indirect losses in Africa estimated at $\$ 2$ billion annually. ${ }^{1-3}$ Direct losses reduce crop yield through damage from feeding larvae that emerge from eggs laid by female flies. ${ }^{1,4,5}$ Indirect losses are a result of quarantine restrictions through introduction of uniform and strict maximum residue levels (MRLs) legislation for pesticides across Europe, causing a reduction in the export market from Africa. ${ }^{6}$ Management of these pests has focused on a number of techniques including the use of commercially available traps that can be combined with food baits, early harvesting, fruit bagging, biological control agents (parasitoids, predators and pathogens), chemical sprays, and orchard sanitation. ${ }^{7,8}$ However, these techniques are not efficacious, with more economically effective complementary tools such as host marking pheromones (HMPs) still needed.

Previous work has demonstrated that fruit flies produce and store their host-marking pheromones in the posterior half of their midgut such that when fecal matter is excreted, it produces large quantities of these compounds. ${ }^{5,9-12}$ To date, the HMPs of fruit flies reported in the literature have been isolated and identified from aqueous or methanol extracts of mature female fecal matter. ${ }^{13-15}$ HMPs have been shown to be biosynthesized and stored in the midgut and released with the fecal matter. ${ }^{16}$

Host marking pheromones have been successfully used to manipulate the oviposition behavior of insects by reducing/ inhibiting subsequent egg laying of conspecifics and hetero- specific species. ${ }^{5,11,12,17}$ For example, the fatty acid glucoside derivative $N$-[15( $\beta$-glucopyranosyl)oxy- 8 hydroxypalmitol]taurine, identified as the HMP from the fecal matter of ovipositing females of the cherry fruit fly Rhagoletis cerasi, was found to significantly reduce conspecific infestation in cherry orchards. $^{14,18}$ Also, the HMP of the Mexican fruit fly Anastrepha ludens, the amino acid derivative $N$-[2,14dimethyl-1-oxopentadecyl)-glutamic acid, identified from fecal matter of the fruit fly was shown to reduce conspecific infestation in the red mombin Spondias purpurea. ${ }^{19}$ Additionally, the efficacy of externally applied fecal matter extracts from female Mediterranean fruit fly Ceratitis capitata on conspecifics has been demonstrated, ${ }^{20}$ but the specific HMP responsible for reducing infestation by the Mediterranean fruit fly is yet to be identified.

Ceratitis capitata and related species C. cosyra, C. fasciventris, and $C$. rosa are indigenous to Africa and are all economically important pests of a wide range of fruits. ${ }^{5,21}$ Once they infest fruits, there is a potential risk of their introduction and establishment into that location, contingent upon environmental conditions. ${ }^{22}$ For example, the larvae of $C$. cosyra in infested mangoes from Africa are among the most commonly intercepted in Europe, ${ }^{23}$ where it is feared that the invasive $C$. cosyra may establish, similar to the now cosmopolitan $C$.

Received: July 10, 2017

Revised: September 11, 2017

Accepted: September 14, 2017

Published: September 15, 2017 
capitata. For this reason, robust, effective, and eco-friendly IPM strategies including use of HMPs are necessary to control these pests. Recent studies, similar to those performed on $C$. capitata, ${ }^{20}$ have demonstrated that related African indigenous fruit flies C. cosyra, C. rosa, and C. fasciventris exhibit host marking behavior, ${ }^{5}$ suggesting their use of HMPs. Additionally, C. cosyra, C. capitata, and C. fasciventris were found to discriminate against the outcome of the host marking behavior of C. cosyra for egg laying, but C. rosa was indifferent to this outcome. This study traced the candidate HMP to the aqueous extract of the fecal matter of females of C. cosyra. However, like the study of the Mediterranean fruit fly, ${ }^{17}$ the chemical identity of the HMP responsible for bioactivity was not disclosed. ${ }^{5}$ The identification of the pheromone responsible for oviposition deterrence would have a potential for its application in the management of several species of fruit flies.

In this study, we sought to determine the identity of the host marking pheromone of C. cosyra. Our objectives were to (i) confirm the bioactivity of aqueous extracts of the fecal matter of C. cosyra against conspecifics; (ii) isolate female specific component(s) (FSC) from the fecal matter and determine its bioactivity; (iii) identify the HMP and test its synthetic equivalent for bioactivity against conspecifics and the heterospecific indigenous species C. rosa, C. fasciventris, C. capitata, and invasive species Z. cucurbitae; and (iv) assess the distribution of the HMP in C. cosyra specific body tissue (ovipositor and hemolymph) and determine the relationship, if any, between HMP concentration and fruit fly age.

\section{MATERIALS AND METHODS}

Insects. The stock colonies of C. cosyra, C. rosa, C. fasciventris, C. capitata, and $Z$. cucurbitae previously identified, ${ }^{24}$ were obtained and raised using the methods described, ${ }^{5,25}$ at the International Centre of Insect Physiology and Ecology, Kenya ( $01^{\circ} 13^{\prime} 25.3^{\prime \prime} \mathrm{S}, 36^{\circ} 53^{\prime} 49.2^{\prime \prime}$ E; $1600 \mathrm{~m} \mathrm{ASL}$ ). The initial $C$. cosyra colony was derived from collections of mango, Mangifera indica L., and marula, Sclerocarya birrea (A. Rich.) Hochst. at Nguruman, Kenya ( $1^{\circ} 47^{\prime} \mathrm{S} ; 36^{\circ} 050^{\prime} \mathrm{E}$; $700 \mathrm{~m} \mathrm{ASL}$ ). C. fasciventris and C. capitata originated from coffee, Coffea arabica $L$. collected from farms in the central highlands of Kenya at Ruiru ( $1^{\circ} 5.72^{\prime}$ S; $36^{\circ} 54.22^{\prime} \mathrm{E}$; $\left.1609 \mathrm{~m} \mathrm{ASL}\right)$, while C. rosa was collected from wild plant Lettowianthus stellatus in the coastal region of Kenya, Mrima hill ( $4^{\circ} 29.32^{\prime}$ S; 39 $\left.15.27^{\prime} \mathrm{E} ; 290 \mathrm{~m} \mathrm{ASL}\right)$. $Z$. cucurbitae was obtained from water melons purchased from a local market in Nairobi, Kenya.

Forty adult flies (10 d old) of each sex were obtained from the stock culture for raising an experimental colony. They were transferred to 30 $\times 30 \times 30 \mathrm{~cm}^{3}$ clear Perspex rearing cages made locally in icipe with fine netting ventilation on one side and maintained on a 4:1 volumetric mixture of sugar (Mumias Sugar Co., Nairobi, Kenya) and an enzymatic yeast hydrolysate (USB Corporation, Cleveland, $\mathrm{OH}$ ). The fruit flies were provided with water ad libitum in $9 \mathrm{~cm}$ Petri dishes filled with pumice granules to prevent drowning. The flies were also provided with three whole ripe mangoes, apple variety for $2 \mathrm{~d}$ as an oviposition substrate. The mangoes were spiked several times using colored push pins sterilized with an ethanol wipe $(1 \mathrm{~mm}$ holes, $\sim 150$ holes/mango). Thereafter, the egg-infested fruits were removed and incubated in $20 \times 12.5 \times 8 \mathrm{~cm}^{3}$ plastic containers covered with a perforated plastic lid (Kenpoly, Nairobi, Kenya). The inner bottom of these containers was cushioned with a thin layer of paper towel to absorb sap produced by the rotting fruits. The paper towels were replaced every $2 \mathrm{~d}$ with clean, dry towels.

On day 10, the time it takes for the five species to reach fourth instar, the paper towel was removed and the larvae-infested, rotten mango washed under running tap water into an incubation container. The fiber, peels, intact seed, and other dirt were removed leaving only the fourth instars, which sank to the bottom of the containers, and recovered through sieving. The brood was then transferred into clean incubation vessels containing $40-60 \mathrm{~mm}$ of sterilized sand for pupation. On day 3 , the sand was soaked in water allowing the puparia to float and were subsequently collected by sieving. The puparia were placed in Petri dishes with moistened filter paper and kept in rearing cages until eclosion. They were subsequently supplied with food and water as described above, and at day 6 , were continuously provided with ripe mangoes for oviposition. The rearing room was maintained at $23-25{ }^{\circ} \mathrm{C}$ and $40-60 \% \mathrm{RH}$ with a photoperiod of $12: 12 \mathrm{~h}$ (L: D) cycle.

Collection of C. cosyra Fecal Matter. The collection and extraction of fecal matter were performed as described previously ${ }^{5,15,20}$ but with the following modifications. Fecal matter of C. cosyra was collected by placing 150 flies of a given sex, either males or females of a known age starting from day 1 after occlusion up to day 30, in a clean glass bottle $(200 \mathrm{~mL})$ fitted with a net lid for five consecutive photoperiods. The collection was initiated in the late afternoon and run until the next morning $(4: 00 \mathrm{pm}-8: 00 \mathrm{am})$ to allow for deposition of their fecal matter in the vessel. Each morning, the flies were released into their respective cages containing food, water, and ripe mangoes until 4:00 pm when they were taken back into their respective bottles. The fecal matter was washed from the jars using $5 \mathrm{~mL}$ of distilled water, freeze-dried on a laboratory scale freeze-dryer, and pooled after $5 \mathrm{~d}$ based on sex. For each day, 10-15 mg of the fecal matter was obtained from each bottle. The feces were stored at $-80{ }^{\circ} \mathrm{C}$ until sufficient quantities for bioassay and extraction were obtained.

Bioassays. For all the bioassays, sexually mature (10-21 d old) female fruit flies were used ${ }^{5,16}$ and a ripe mango of apple variety selected as an oviposition substrate owing to its economic importance. ${ }^{26}$ The mango was sliced lengthwise into two equal halves, with the endocarp and mesocarp carefully scooped out. The remaining exocarp was thoroughly washed with distilled water and fitted in covers of $50 \mathrm{~mm}$-diameter Petri dish with the rinds on the top surface. The size of each oviposition substrate was $\sim 20.4 \mathrm{~cm}^{2}$ (surface area) and 5 $\mathrm{mm}$ thick. Oviposition reduction response in the fruit flies was studied in dual-choice tests as described. ${ }^{5}$ Female fruit flies (100) of each species were observed to choose between ovipositing on:

(a) Experiment 1: a marked mango slice treated with $1 \mathrm{~mL}$ of aqueous fecal matter solution $(10 \mathrm{mg} / \mathrm{mL} ; 100$ insect equivalent) or a control (treated with $1 \mathrm{~mL}$ distilled water). The tests were conducted for conspecifics (C. cosyra female aqueous fecal matter extract using C. cosyra females).

(b) Experiment 2: a marked mango slice treated with $1 \mathrm{~mL}$ known concentration of C. cosyra female specific compound (FSC) (1 $\mathrm{mg} / \mathrm{mL}, 5$ or $10 \mathrm{mg} / \mathrm{mL}$ ) versus a control (treated with $1 \mathrm{~mL}$ distilled water) using C. cosyra females.

(c) Experiment 3: a marked mango slice treated with $1 \mathrm{~mL}$ known concentration of GSH $(1 \mathrm{mg} / \mathrm{mL}, 5$ or $10 \mathrm{mg} / \mathrm{mL})$ and a control (treated with $1 \mathrm{~mL}$ distilled water) using C. cosyra, $C$. rosa, C. fasciventris, C. capitata, and Z. cucurbitae females.

Test samples and controls soaked in cotton swabs were applied to the mango substrate. The 100 fruit flies used for each experiment were grouped into 10 batches of 10 fruit flies with each batch representing a replicate. Each replicate used ten pair of oviposition substrates placed at the center of the observation cage, side by side and in contact to each other to allow fruit fly movement to allow for searching for oviposition sites. For each observation, one new pair of mango slices prepared from one mango was used to minimize differences in their chemistry, which could influence choice of the fruit flies, and their relative positions randomly varied before introducing the next fruit fly.

In all experiments involving oviposition, total oviposition time was measured beginning $30 \mathrm{~s}$ after fruit fly introduction into the observation cage and the session ended only if the female inserted its aculeus into the fruit pulp, keeping her ovipositor in a perpendicular position to the surface, eggs deposited, and dragged the protracted ovipositor on the surface of the oviposition substrate before flying away from the host. All fruit flies were only allowed to oviposit once. After an observation session was terminated for a female, she was returned to the rearing cage. The maximum total oviposition time 
allowed per observation was $30 \mathrm{~min}$. The fruit flies that failed to make a choice between the treated substrate and control after $30 \mathrm{~min}$ were deemed to be nonresponsive and were replaced by fresh fruit flies.

Chemical Analyses. Fecal Matter. The fecal matter of C. cosyra (1 $\mathrm{mg}$ ) previously collected from both males and females of specific age was separately dissolved in $1 \mathrm{~mL}$ of $0.01 \%$ formic acid/acetonitrile (95:5, LC-MS grade Chromasolv, Sigma-Aldrich, St. Luis, MO), vortexed for $30 \mathrm{~s}$, sonicated for $30 \mathrm{~min}$, and centrifuged at $14000 \mathrm{rpm}$ for $5 \mathrm{~min}$ to remove any insoluble material, after which $5 \mu \mathrm{L}$ of the supernatant was analyzed on a VP series HPLC system (Shimadzu, Kyoto, Japan) equipped with a prominence SPD-M20 diode array detector (wavelength set at $190-360 \mathrm{~nm}$ for UV and $360-700 \mathrm{~nm}$ for visible range). The column oven was set at $30{ }^{\circ} \mathrm{C}$ with the following column parameters, $250 \mathrm{~mm} \times 10 \mathrm{~mm}$ i.d., $5 \mu \mathrm{m}$, ACE 5 C- 18 column (Advance Chromatography Technologies, Aberdeen, Scotland). The mobile phases consisted of water (A) and acetonitrile (B), each containing $0.01 \%$ formic acid. The following gradient program was employed $0 \mathrm{~min}, 5 \% \mathrm{~B}$; 0-5 min, 5-50\% B; 5-10 min, 50-80\% B; $10-15 \mathrm{~min}, 80-100 \%$ B; $15-25$ min $100 \%$ B; $25-30$ min $5 \%$ B; $30-$ $35 \mathrm{~min} 5 \% \mathrm{~B}$. The flow rate was held constant at $1 \mathrm{~mL} / \mathrm{min}^{27}$

To obtain sufficient quantities of C. cosyra FSC for bioassay, $100 \mathrm{~g}$ of $C$. cosyra female fecal matter collected from sexually mature females $(10-21 \mathrm{~d}$ old $)$ was dissolved in $200 \mathrm{~mL}$ of the same solvent, vortexed for $30 \mathrm{~s}$, sonicated for $30 \mathrm{~min}$, and centrifuged at $14000 \mathrm{rpm}$ for 5 min, after which $100 \mu \mathrm{L}$ of the supernatant was injected into semipreparative column $(250 \mathrm{~mm} \times 10 \mathrm{~mm}$ i.d., $5 \mu \mathrm{m}$, ACE $5 \mathrm{C}-18$ column (Advance Chromatography Technologies, Aberdeen, Scotland) installed on an HPLC-PDA and the peak at retention time 4.5 $\mathrm{min}$, monitored at $220 \mathrm{~nm}$ wavelength collected from $\sim 1200$ runs over a period of 3 months, pooled, and freeze-dried to yield $2 \mathrm{~g}$ of FSC. Each day's collection was stored at $-80{ }^{\circ} \mathrm{C}$ until sufficient quantities $(2 \mathrm{~g})$ for bioassay were obtained.

The HPLC fractionated pure FSC from C. cosyra $(1 \mathrm{mg})$ was dissolved in $1 \mathrm{~mL}$ of $0.01 \%$ formic acid/acetonitrile $(95 ; 5, \mathrm{v} / \mathrm{v}) \mathrm{LC}-$ MS grade solvent, vortexed for $30 \mathrm{~s}$, and centrifuged at $14000 \mathrm{rpm}$ for 5 min after which $0.2 \mu \mathrm{L}$ of the supernatant was analyzed by LCQTOF-MS. Chromatographic separation was achieved on an Acquity UPLC I-class system (Waters Corp., Milford, MA). The column used was a $250 \mathrm{~mm} \times 4.6 \mathrm{~mm}$ i.d., $5 \mu \mathrm{m}$, ACE C-18 column (Advance Chromatography Technologies, Aberdeen, Scotland) with a heater turned off and an autosampler tray cooled to $5{ }^{\circ} \mathrm{C}$. Mobile phases of water (A) and acetonitrile (B), each with $0.01 \%$ formic acid, were employed. The following gradient was used $0 \mathrm{~min}, 5 \% \mathrm{~B} ; 0-3 \mathrm{~min}, 5-$ $30 \%$ B; 3-6 min, 30\% B; 6-7.5 min, 30-80\% B; 7.5-10.5 min, $80 \%$ B; $10.5-13.0 \mathrm{~min}, 80-100 \% \mathrm{~B}, 13-18 \mathrm{~min}, 100 \%$ B; $18-20 \mathrm{~min}$, $100-5 \% \mathrm{~B} ; 20-22 \mathrm{~min}, 5 \% \mathrm{~B}$. The flow rate was held constant at 0.7 $\mathrm{mL} / \mathrm{min}$. The injection volume was $0.2 \mu \mathrm{L}$.

The UPLC system was interfaced by electrospray ionization to a Synapt G2-Si QTOF-MS (Waters) operated in full scan $\mathrm{MS}^{\mathrm{E}}$ in positive mode. Data were acquired in resolution mode over the range $\mathrm{m} / \mathrm{z} 100-700$ with a scan time of $1 \mathrm{~s}$ using a capillary voltage of 0.5 $\mathrm{kV}$, sampling cone voltage of $40 \mathrm{~V}$, source temperature of $100^{\circ} \mathrm{C}$, and desolvation temperature of $350{ }^{\circ} \mathrm{C}$. The nitrogen desolvation flow rate was $500 \mathrm{~L} / \mathrm{h}$. For the high-energy scan function, a collision energy ramp of $25-45 \mathrm{eV}$ was applied in the $\mathrm{T}$-wave collision cell using ultrahigh purity argon $(\geq 99.999 \%)$ as the collision gas. A continuous lock spray reference compound (leucine enkephalin; $[\mathrm{M}+\mathrm{H}]^{+}=$ 556.2766) was sampled at $10 \mathrm{~s}$ intervals for centroid data mass correction. The mass spectrometer was calibrated across the mass range $50-1200-\mathrm{Da}$ mass range using a $0.5 \mathrm{mM}$ sodium formate solution prepared in 90:10 propan-2-ol:water $(90 ; 10, \mathrm{v} / \mathrm{v})$. MassLynx version 4.1 SCN 712 (Waters) was used for data acquisition and processing. The elemental composition was generated for every analyte. Potential assignments were calculated using the monoisotopic masses with specifications of a tolerance of $10 \mathrm{ppm}$ deviation and both odd- and even-electron states possible. The number and types of expected atoms were set as follows: carbons $\leq 50$; hydrogens $\leq 100$; oxygens $\leq 50$; nitrogens $\leq 10$; chlorines $\leq 10$; sulfurs $\leq 10$. Data acquisition and analysis by LC-QTOF-MS were based on the following defined factors: mass accuracy $(\mathrm{ppm})=1000000 \times$ (calculated mass - accurate mass)/calculated mass; fit conf \% refers the confidence with which the measured mass (accurate mass) matches the theoretical isotope models of the elemental composition in the list. The empirical formula generated was used to predict structures that were proposed based on the online database (METLIN, ChemSpider and ChemCalc, fragment ion calculator), fragmentation pattern, literature, and authentic standard (L-glutathione reduced, 98\% purity) (Sigma-Aldrich, St. Louis, MO).

Ovipositor. Ten sexually mature females $(10 \mathrm{~d}$ old $)$ of $C$. cosyra were dissected and the ovipositor tips excised into a vial containing $500 \mu \mathrm{L}$ of $0.01 \%$ formic acid/acetonitrile (95:5), vortexed for $1 \mathrm{~min}$, extracted by ultrasonication in a sonication bath for $30 \mathrm{~min}$, centrifuged at $13000 \mathrm{rpm}$ for $5 \mathrm{~min}$ at $5{ }^{\circ} \mathrm{C}$, and the supernatant analyzed using LC-QTOF-MS. This was repeated three times from different batches of 10 females and the samples similarly analyzed.

Hemolymph. Hemolymph collection and extraction was performed as previously described. ${ }^{28}$ Sexually mature males and females (10-15 of each sex) of $C$. cosyra (10-12 d old) were separately held in a waxed bottom dish with pins pierced through the wings and head. A small slit was made down the center line of the thorax after which the hemolymph was allowed to flow into a calibrated $5 \mu \mathrm{L}$ disposable micropipettes (by gravity). The hemolymph was pooled separately based on sex to obtain sufficient quantities for extraction $(3 \mu \mathrm{L})$; approximately, $0.3 \mu \mathrm{L}$ of hemolymph was obtained per insect. The hemolymph was then transferred into a vial containing $500 \mu \mathrm{L}$ of $0.01 \%$ formic acid/methanol (30:70), vortexed for $1 \mathrm{~min}$, sonicated for $30 \mathrm{~min}$, centrifuged at $13000 \mathrm{rpm}$ for $5 \mathrm{~min}$ at $5{ }^{\circ} \mathrm{C}$ to remove any precipitated protein, and the supernatant analyzed using LC-QTOFMS. This was repeated three times with a different batch of males and females.

Acid Hydrolysis of Female-Specific Compound. The FSC from C. cosyra $(10 \mathrm{mg})$ was transferred into a $5 \mathrm{~mL}$ microreaction vial into which $2 \mathrm{~mL}$ of $6 \mathrm{~N} \mathrm{HCl}$ was added and closed after careful introduction of nitrogen gas. The sample was hydrolyzed for $24 \mathrm{~h}$ at $110^{\circ} \mathrm{C}$. After the hydrolysis, the mixtures were evaporated to dryness under vacuum. The hydrolysates were reconstituted in $1 \mathrm{~mL}$ of $0.01 \%$ formic acid/acetonitrile (95:5), vortexed for $30 \mathrm{~s}$, sonicated for $30 \mathrm{~min}$, and then centrifuged at $14000 \mathrm{rpm}$, and the supernatant analyzed by LC-QTOF-MS. This was repeated three times using different samples.

Relationship between Glutathione Amount in Fecal Matter and C. cosyra Age. The fecal matter $(10 \mathrm{mg})$ of C. cosyra was obtained as earlier described starting from day one after eclosion and stopped at day 30 when majority of the flies were dead. On a daily basis, the fecal matter for both males and females were separately washed off the jar with $5 \mathrm{~mL}$ of distilled water, freeze-dried, redissolved in $1 \mathrm{~mL}$ of $0.01 \%$ formic acid/acetonitrile (95:5), vortexed for $30 \mathrm{~s}$, sonicated for $30 \mathrm{~min}$, and centrifuged at $14000 \mathrm{rpm}$ for 5 min, after which $10 \mu \mathrm{L}$ of the supernatant were analyzed by LC-MS. The same procedure was used to analyze the extracting solvents and three different samples $(10 \mathrm{mg}$ each) obtained from the rearing diet.

The LC-MS operating conditions were as follows: a quaternary LC pump (Model 1200) coupled to Agilent MSD 6120-Single quadruple MS with electrospray source (Palo Alto, CA) was used. The system was controlled using ChemStation software (Hewlett-Packard). Reversed-phase liquid chromatography was performed on an Agilent technologies 1200 infinite series, Zorbax SB C-18 column, $2.1 \times 50$ $\mathrm{mm}^{2}, 1.8 \mu \mathrm{m}$ (Phenomenex, Torrance, $\mathrm{CA}$ ) using a gradient program and mobile solvents similar to the LC method described above. The injection volume was $10 \mu \mathrm{L}$, and data were acquired in a full-scan positive-ion mode using a $100-800 \mathrm{~m} / z$ scan range. The dwell time for each ion was $50 \mathrm{~ms}$. Other parameters of the mass spectrometer were as follows: capillary voltage, $3.0 \mathrm{kV}$; cone voltage, $70 \mathrm{~V}$; extract voltage, $5 \mathrm{~V}$; RF voltage, $0.5 \mathrm{~V}$; source temperature, $110^{\circ} \mathrm{C}$; nitrogen gas temperature for desolvation, $380{ }^{\circ} \mathrm{C}$; and nitrogen gas flow for desolvation, $400 \mathrm{~L} / \mathrm{h}$. Serial dilutions of glutathione standard (1-100 $\mathrm{ng} / \mu \mathrm{L}$ ) were analyzed by LC-MS in full scan mode to generate linear calibration curve (peak area vs concentration) with the following equation; $\left[y=6008.9 x-5250.3\left(R^{2}=0.9987\right)\right]$, which served as a basis for external quantification. 
Statistical Analyses. The number insects responding to the treatments and controls in the dual choice assays was analyzed by Chisquare goodness of fit to assess (a) C. cosyra females discrimination to aqueous C. cosyra females fecal matter compared to control (b) $C$. cosyra females discrimination to different doses of aqueous C. cosyra FSC compared to control (c) C. cosyra, C. rosa, C. fasciventris, C. capitata, and Z. cucurbitae females discrimination to different doses of GSH against control. Nonrespondents were not included in the analysis. Analysis of HPLC profiles involved comparison of retention times of peaks of individual chemical components. The peak area from the total ion chromatogram corresponding to GSH obtained from LC-MS analysis was used to compute concentrations from the calibration curve. Concentration of C. cosyra FSC determined at different insect ages was expressed as mean \pm standard error. Analysis of variance was carried for all the concentrations for the various ages and means were separated using Tukey's studentized HSD. Rstatistical program version 2.11.0 software ${ }^{29}$ was used to perform the statistical analyses and all tests were performed at 5\% significance level.

\section{RESULTS AND DISCUSSION}

Bioactivity of C. cosyra Fecal Matter Extract Confirmed. First tested was whether the HMP modulated C. cosyra oviposition behavior. As previously found, ${ }^{5}$ mango slices treated with the aqueous extract of the fecal matter of C. cosyra significantly reduced oviposition responses in conspecific females (Figure 1A). Ovipositing females on average required

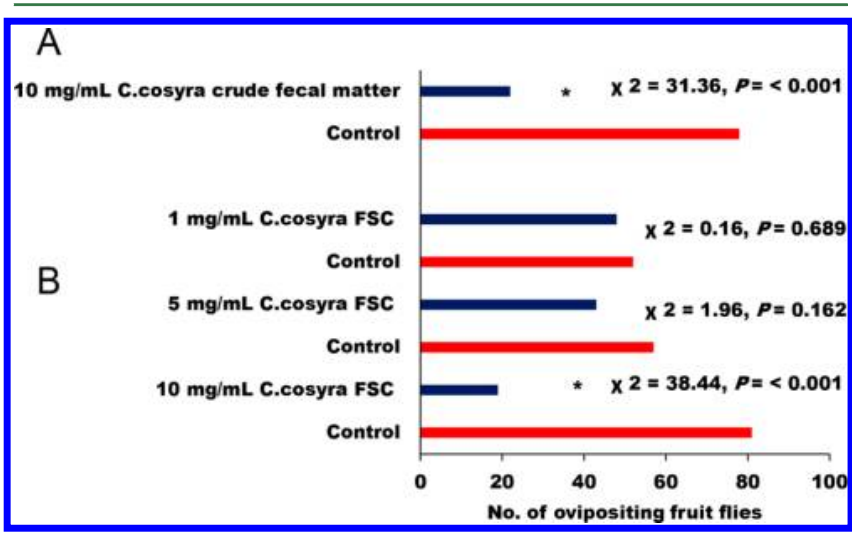

Figure 1. Discrimination of oviposition substrates treated with (A) 10 $\mathrm{mg} / \mathrm{mL}$ aqueous solutions of fecal matter by conspecific females and (B) aqueous solution of FSC isolated from fecal matter of C. cosyra by conspecific females. $*$, Significantly different at 0.05 .

three times longer to assess the suitability of the treated oviposition substrate than controls. This suggests that they recognized that the treated hosts were marked with a compound whose volatility was relatively low and acted at close range, as well as present at a concentration within the levels to influence their oviposition decision. C. cosyra ovipositing female performance on the treated and control hosts is a survival strategy to minimize the overexploitation of the same resource for egg laying by conspecifics to ensure success and fitness of their progeny in terms of access to food resources and maximum use of nutrients for development. Most studies focusing on insect host marking pheromones have made similar observations. For example, in the scarce large blue butterfly, Phengaris (Maculinea) teleius, ${ }^{30}$ pepper weevil, Anthonomus eugenii, ${ }^{31}$ egg parasitoid Trissolcus basalis, ${ }^{32}$ Pieris brassicae, and Pieris rapae. ${ }^{33}$

Bioassay-Guided Fractionation Isolates Female-Specific Component. Next, chemical analysis of the aqueous extract of the fecal matter collected from both males and females of $C$. cosyra at different ages by HPLC revealed the presence of a female-specific peak at retention time $4.5 \mathrm{~min}$ with UV absorption at $\lambda$ max $_{2} 20 \mathrm{~nm}$ (Figure 2).

To aid in identifying the component that appeared to be a biomarker for gravid female C. cosyra FSC, the LC-MS profiles of the aqueous extracts of the fecal matter of females were compared with a similar extract obtained from the rearing diet. FSC was present only in the aqueous extracts of the fecal matter of 6- to 30-d old gravid females.

Fractionation of the aqueous extracts of fecal matter obtained from 3 and $6 \mathrm{~d}$ old females and males by liquid chromatography gave a FSC in $6 \mathrm{~d}$ but not $3 \mathrm{~d}$ old female fecal matter. This component was also absent in the fecal matter of males at both ages. These results suggest that the production and release of the FSC is dependent on the developmental state of the female. The physiological basis for this was not investigated but these findings suggest that in females the biochemical pathway for synthesis of the FSC is switched on as the female reaches a specific age of maturity. As such, it is possible that the onset of the production and release of the FSC may occur earlier than 6 d. Age-dependent pheromone production and release has important implications in the biology and ecology of insects because they influence certain physiological processes such as reproduction, feeding, oviposition, and development. ${ }^{34-39} \mathrm{An}$ investigation of the physiological basis for production the FSC would enhance our understanding of the behavioral ecology of females.

To obtain enough FSC for bioassays and chemical analyses, $100 \mathrm{~g}$ of crude female fecal matter was fractionated by semipreparative HPLC to obtain $2 \mathrm{~g}$ of the FSC. In doseresponse tests at concentrations of 1,5 , and $10 \mathrm{mg} / \mathrm{mL}(1 \mathrm{mg}$ of FSC $=95$ insect fecal matter equivalents), host discrimination in conspecifics increased with increasing dose with $10 \mathrm{mg} / \mathrm{mL}$ of FSC eliciting the highest oviposition reducing response in females which almost mirrored the bioactivity of the crude fecal matter extract tested at the same dose $\left(\chi^{2}=38.44 ; \mathrm{d} f=1 ; P<0.001\right)$ (Figure 1B). Furthermore, ovipositing fruit flies required longer times to assess the suitability of the treated oviposition substrate compared to the control.

These results confirm the sensitivity and suitability of our extraction method, avoiding possible degradation of the bioactive component. They are also consistent with previous studies which found that fecal matter and their aqueous extracts obtained from the related fruit flies C. capitata, C. rosa, and C. fasciventris ${ }^{5}$ and those of the cherry fruit fly Rhagoletis cerasi ${ }^{14,40}$ and the Mexican fruit fly Anastrepha ludens contained chemicals that reduced oviposition responses in conspecifics. ${ }^{19}$

LC-QTOF MS Identification of C. cosyra HMP. Similar to the analysis of crude fecal matter aqueous extract, analysis of this bioactive fraction by LC-QTOF-MS showed a major peak at retention time $2.38 \mathrm{~min}$ (Figure 3), which gave a molecular ion peak $[\mathrm{M}+\mathrm{H}]^{+}$at $\mathrm{m} / z 308.0928$ having a molecular formula of $\mathrm{C}_{10} \mathrm{H}_{18} \mathrm{~N}_{3} \mathrm{O}_{6} \mathrm{~S}$. Library search of $\mathrm{m} / z 308.0928$ returned the tripeptide glutathione as a compound that fit the predicted empirical formula. Acid digestion of the bioactive fraction followed by LC-MS analysis identified the digestion products as the amino acids glycine $(\mathrm{G})$, cysteine $(\mathrm{C})$, and glutamic acid (E). A fragment ion calculator search of the six possible arrangements, ECG, GCE, EGC, GEC, CEG, or CGE of the tripeptide predicted a $\mathrm{N}-\mathrm{C}$ terminal structure of the tripeptide as glutamyl-cysteinyl-glycine (ECG). The tripeptide structure was supported by the presence of major expected 


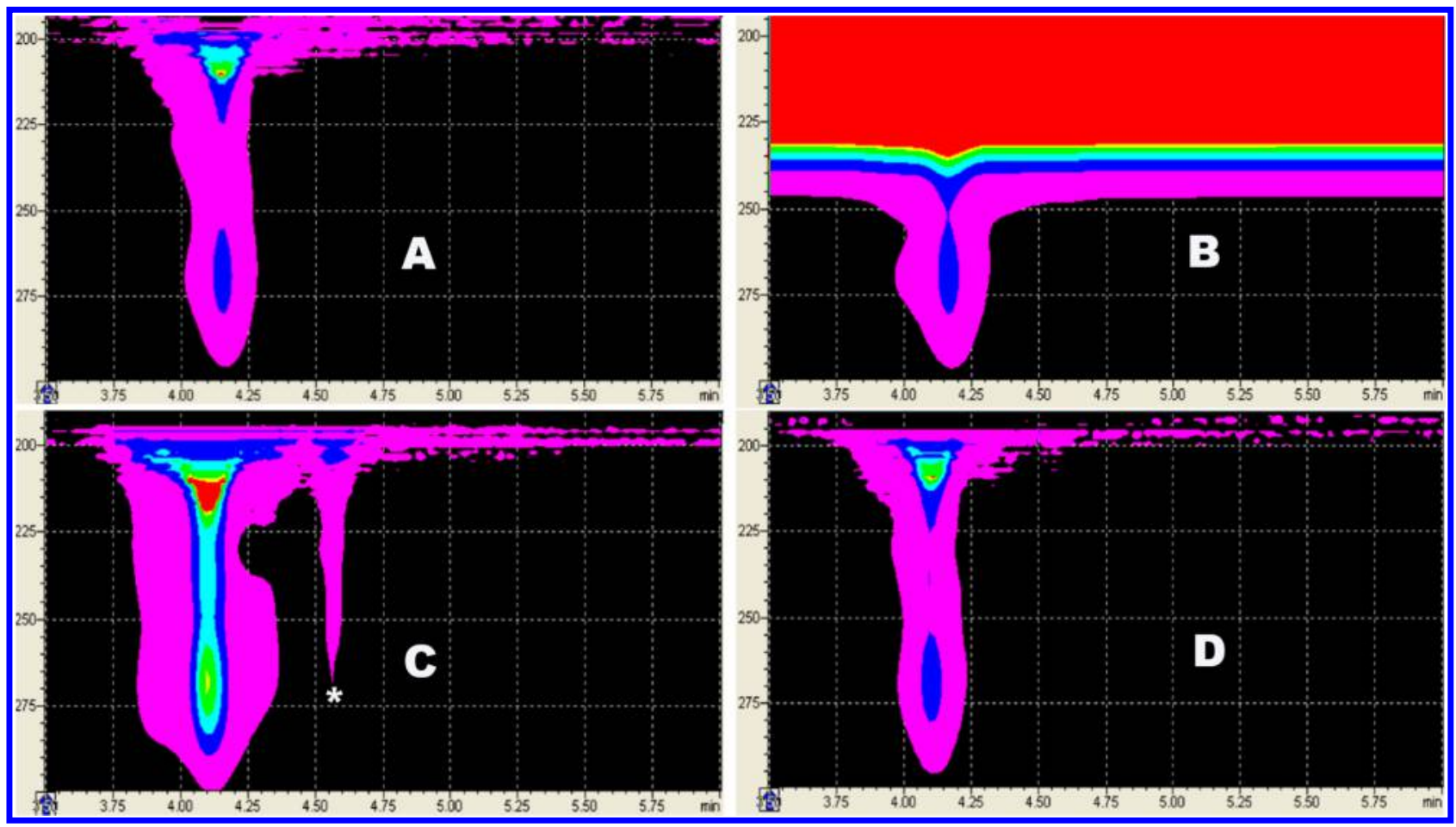

Figure 2. HPLC-PDA contour view of aqueous extract of the fecal matter of C. cosyra of (A) 3 day old females, (B) 3 day old males, (C) 6 day old females, and (D) 6 day old males. *, Peak of female specific component (FSC) of C. cosyra.

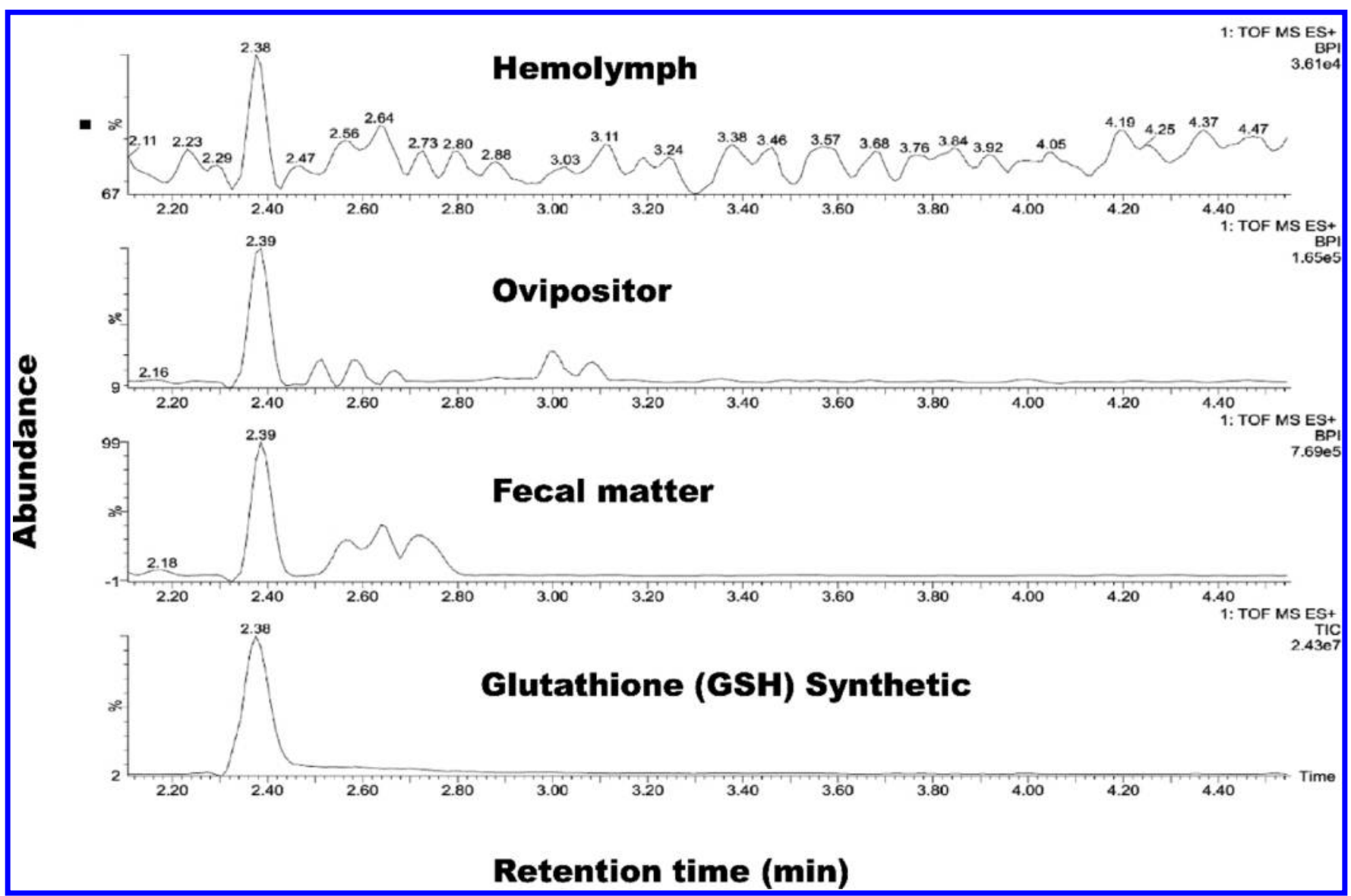

Figure 3. LC-QTOF-MS representative total ion chromatogram showing detection of GSH in gravid female C. cosyra hemolymph, ovipositor, and fecal matter compared to the authentic compound. The retention time of GSH is $2.38 \mathrm{~min}$. 
fragments of monoisotopic masses for $z_{2}, y_{2}$, and $b_{2}$ ions $m / z$ 162,179 , and $233^{41}$ and confirmed the identity of the HMP of C. cosyra as glutathione based on comparison of mass spectra data, retention time, and coinjection of the natural product with an authentic standard. To determine whether glutathione was present in other body tissues of females of C. cosyra, the aqueous extracts of both the ovipositor and hemolymph were similarly analyzed by LC-QTOF-MS. Glutathione was detected in the two tissues of $10 \mathrm{~d}$ old gravid females.

Chemical analysis identified unambiguously the FSC as the tripeptide glutathione consisting of glycine, cysteine, and glutamic acid. This suggests that GSH is likely synthesized from these three amino acids ingested from the rearing diet of the fruit fly. Future research will evaluate whether GSH would be detected in C. cosyra fecal matter when reared on varying diets or other combinations of these amino acids. Interestingly, the HMP of C. cosyra is highly distinct when compared to the other HMPs identified from the fecal matter of other fruit flies; $N$-[15( $\beta$-glucopyranosyl)oxy-8 hydroxypalmitol $]$-taurine, identified from the cherry fruit fly Rhagoletis cerasi, ${ }^{14,18}$ and $N-[2,14-$ dimethyl-1-oxopentadecyl)-glutamic acid, identified from the Mexican fruit fly Anastrepha ludens. However, the HMP of $C$. cosyra appears to be more closely related to the HMP of the Mexican fruit fly, which contains glutamic acid. In contrast, the HMP of $R$. cerasi is a fatty acid glucoside. Nonetheless, it is reasonable to assume that in general and irrespective of the fruit fly species and complexity of the structure of the HMP, binding of the components involves at least an amino acid or a carbohydrate to enhance solubility in water.

Bioactivity of C. cosyra HMP Glutathione. In bioassays, glutathione reduced oviposition responses of the five fruit fly species C. cosyra, C. fasciventris, C. rosa, C. capitata, and Z. cucurbitae in a dose-response manner (Figures 4A-C). The oviposition reducing response was both concentration and species-dependent, especially at the highest concentration of 10 $\mathrm{mg} / \mathrm{mL}$; with $C$. cosyra $\left(\chi^{2}=54.76 ; \mathrm{d} f=1, P<0.001\right), C$. fasciventris $\left(\chi^{2}=64.00 ; \mathrm{d} f=1, P<0.001\right)$, and $C$. rosa $\left(\chi^{2}=\right.$ 60.84; $\mathrm{d} f=1 ; P<0.001)$, being more responsive to the HMP than $C$. capitata $\left(\chi^{2}=10.24 ; \mathrm{d} f=1 ; P=0.001\right)$ and $Z$. cucurbitae $\left(\chi^{2}=31.36 ; \mathrm{d} f=1 ; P<0.001\right)$ (Figure 4C). Consistent with our previous results on oviposition responses of $C$. cosyra, the ovipositing heterospecific fruit flies also required on the average an additional 1-3 min longer to assess the suitability of the oviposition substrate treated with increasing dose of GSH. The GSH concentration of $10 \mathrm{mg} / \mathrm{mL}$ elicited the longest assessment time from ovipositing females compared to the control.

Our results showed that the five fruit fly species $C$. cosyra, $C$. fasciventris, C. rosa, C. capitata, and $Z$. cucurbitae responses to GSH treated mango slices was both concentration- and speciesdependent. C. cosyra, C. fasciventris, and C. rosa were more sensitive to GSH at the most effective concentration of $10 \mathrm{mg} /$ $\mathrm{mL}$ than $C$. capitata and Z. cucurbitae. It has been reported that the host range of $C$. cosyra is narrow, mainly infesting mango and marula, ${ }^{23}$ whereas the relationship between the other fruit fly species and host fruits may be less specific. Thus, intra- and interspecific recognition and sensitivity to GSH by these fruit fly species may be influenced also by host factors including semiochemicals. Future studies on the role of host semiochemicals on fruit fly discrimination of pheromone-marked hosts for oviposition are warranted. Furthermore, since chemoreceptors have been shown to play a role in the detection of semiochemicals, ${ }^{42}$ elucidating the detection

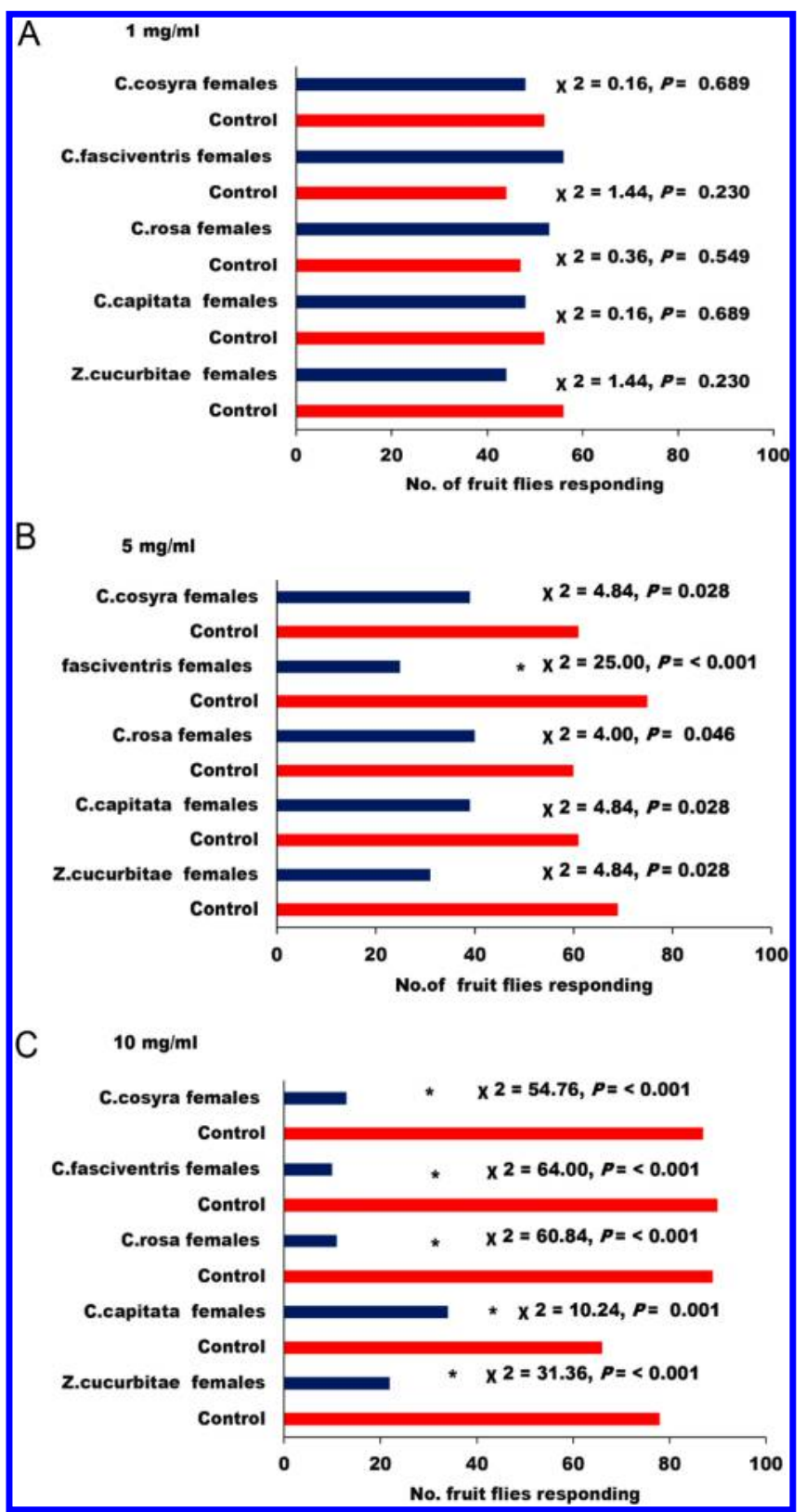

Figure 4. Discrimination of oviposition substrates treated with aqueous solutions of synthetic glutathione (GSH) by $C$. cosyra, C. fasciventris, C. rosa, C. capitata, and Z. cucurbitae at (A) $1 \mathrm{mg} / \mathrm{mL},(B)$ $5 \mathrm{mg} / \mathrm{mL}$, and $(\mathrm{C}) 10 \mathrm{mg} / \mathrm{mL}$. *, Significantly different at 0.05 .

mechanism of C. cosyra HMP by conspecifics and heterospecifics is recommended.

Relationship between Glutathione Amount in Fecal Matter and C. cosyra Age. To determine the relationship between amount of GSH in fecal matter and age of C. cosyra, fecal matter was collected and analyzed from $1,3,6,9,12,15$, $18,21,24,27$, and $30 \mathrm{~d}$ old adult females. GSH amount increased from $93.4 \pm 0.36 \mu \mathrm{g} / \mathrm{mg}$, detected in the fecal matter of $6 \mathrm{~d}$ old gravid females to an optimal amount of $104.1 \pm 0.4$ $\mu \mathrm{g} / \mathrm{mg}$ and $106.0 \pm 1.18 \mu \mathrm{g} / \mathrm{mg}$ realized in 12 and $15 \mathrm{~d}$ old females, respectively, before dropping. Overall, the amount of GSH in fecal matter correlated positively $\left(R^{2}=0.8817\right)$ with the age of gravid females (Figure 5).

This implies that age is an important factor for the successful release of enzymes that catalyze the synthesis of the HMP. 


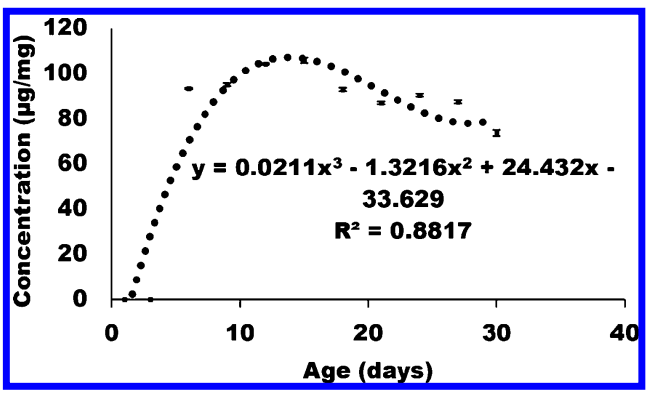

Figure 5. Relationship between female age (days) and the amount $(\mu \mathrm{g} / \mathrm{mg})$ of glutathione detected in fecal matter of C. cosyra. Concentrations of FSC for the various insect age bearing the same letter are not significantly different $(P=0.05$, Tukey's, HSD test).

Thus, the HMP is a critical factor in the reproductive biology of sexually mature females of this fruit fly species, confirming previous findings by other researchers. ${ }^{19,35,40,43}$ Our results also suggest the potential wider applicability of the host marking pheromone of $C$. cosyra in fruit fly management in important agricultural commodities. Furthermore, detection of the GSH in the ovipositor and hemolymph of $10 \mathrm{~d}$ old females suggests that this pheromone is synthesized in the gut of C. cosyra and thereafter transported into the hemolymph and into the ovipositor. The fact that GSH level was 5-10-times higher in the aqueous extract of the fecal matter than in similar extracts of the ovipositor and hemolymph of females suggests that apart from the amounts of the pheromone deposited via the ovipositor after egg laying, females can also protect their progeny from conspecifics and heterospecifics using their fecal matter directly or indirectly on or near the host.

Several studies have identified GSH as a generalist compound in many organisms including plants, animals, fungi, some bacteria, and archaea. ${ }^{43,44}$ In addition to the role it plays in the synthesis of proteins and DNA, transport, enzyme activity, metabolism, and protection of cells, ${ }^{45,46}$ it has also been shown to play a major role in the excretion of xenobiotics $^{44}$ and toxic metals ${ }^{47}$ in many organisms. Cysteineglutathione disulfide, a GSH derivative has also been reported as a sex pheromone in the marine polychaete Nereis succinea. ${ }^{48}$ In insects, GSH has been found to play a role in insecticide resistance through its conjugation with the insecticide to produce water-soluble metabolites that are readily excreted ${ }^{49}$ and in the detoxification of toxic plant metabolites and allelochemicals including glucosinolates, hydroxamic acids, and furocoumarins ingested by herbivorous insects. ${ }^{49,50}$ In addition to these roles, the present study has found GSH as a HMP released by ovipositing females of $C$. cosyra to reduce the overexploitation of the same host for egg laying by conspecifics and heterospecifics.

The identification of GSH as an oviposition reducing semiochemical in five fruit fly species suggests that it can be deployed as a component for the integrated management of some species of fruit flies. Further development and optimization of C. cosyra HMP for use in fruit fly IPM programs in Africa are warranted as well as investigation of the applicability of this HMP for other fruit fly genera.

\section{ASSOCIATED CONTENT}

\section{S Supporting Information}

The Supporting Information is available free of charge on the ACS Publications website at DOI: 10.1021/acs.jafc.7b03164.
Total oviposition times recorded using C. cosyra FSC and GSH; LC-MS analyses of crude frass, blank, and diet; mass spectrum showing natural and synthetic GSH (PDF)

\section{AUTHOR INFORMATION}

\section{Corresponding Author}

*E-mail: btorto@icipe.org. Phone: +254 20863 2000. Fax: +254208632001.

\section{ORCID}

John J. Beck: 0000-0002-0696-5060

Baldwyn Torto: 0000-0002-5080-9903

\section{Funding}

We gratefully acknowledge the financial support for this research by the following organizations and agencies: USDAARS Project No. 58-6615-3-011-F; Swedish International Development Cooperation Agency (SIDA) for a studentship to Xavier Cheseto; UK's Department for International Development (DFID); the Swiss Agency for Development and Cooperation (SDC); and the Kenyan Government. The views expressed herein do not necessarily reflect the official opinion of the donors.

\section{Notes}

The authors declare no competing financial interest.

"II Deceased.

\section{ACKNOWLEDGMENTS}

We thank Daisy Salifu for assistance with statistical analysis, and Onesmus Wanyama, John Kiilu, and Richard Ochieng for their technical support. Mention of trade names or commercial products in this publication is solely for the purpose of providing specific information and does not imply recommendation or endorsement by the USDA.

\section{REFERENCES}

(1) Ekesi, S.; Kelemu, S. Fruit Fly Bait Production Facility Launched in Kenya Plant Will Produce Icipe Fruitfly Mania; ICIPE, 2016. http:// www.icipe.org/news/fruit-fly-bait-production-facility-launched-kenya (accessed May 16, 2017).

(2) Lux, S. A.; Ekesi, S.; Dimbi, S.; Samira, M.; Billah, M. MangoInfesting Fruit Flies in Africa: Perspectives and Limitations of Biological Approaches to Their Management 2002, 1.

(3) Mwatawala, M. W.; White, I. M.; Maerere, A. P.; Senkondo, F. J.; De Meyer, M. A new invasive Bactrocera species (Diptera: Tephritidae) in Tanzania. African Entomol. 2004, 12, 154-158.

(4) Vaníčková, L.; Virgilio, M.; Tomčala, A.; Bř́zová, R.; Ekesi, S.; Hoskovec, M.; Kalinová, B.; Do Nascimento, R. R.; De Meyer, M. Resolution of three cryptic agricultural pests (Ceratitis fasciventris, $C$. anonae, C. rosa, Diptera: Tephritidae) using cuticular hydrocarbon profiling. Bull. Entomol. Res. 2014, 104, 631-638.

(5) Kachigamba, D. L.; Ekesi, S.; Ndung'u, M. W.; Gitonga, L. M.; Teal, P. E. A.; Torto, B. Evidence for potential of managing some African fruit fly species (Diptera: Tephritidae) using the mango fruit

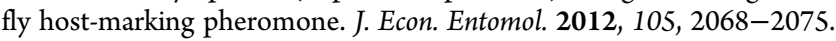

(6) de Graaf, J. Host status of avocado ('Hass') to Ceratitis capitata, Ceratitis rosa, and Ceratitis cosyra (Diptera: Tephritidae) in South Africa. I. Econ. Entomol. 2009, 102, 1448-1459.

(7) Rwomushana, I.; Ekesi, S.; Ogol, C. K. P. O.; Gordon, I. Mechanisms contributing to the competitive success of the invasive fruit fly Bactrocera invadens over the indigenous mango fruit fly, Ceratitis cosyra: The role of temperature and resource pre-emption. Entomol. Exp. Appl. 2009, 133, 27-37. 
(8) Silva, M. A.; Bezerra-silva, G. C. D.; Mastrangelo, T. The Host Marking Pheromone Application on the Management of Fruit Flies - A Review. Braz. Arch. Biol. Technol. 2012, 55, 835-842.

(9) Roitberg, B. D.; Prokopy, R. J. Insects That Mark Host Plants. BioScience 1987, 37, 400-406.

(10) Roitberg, B. D.; Cairl, R. S.; Prokopy, R. J. Oviposition deterring pheromone influences dispersal distance in tephritid fruit flies. Entomol. Exp. Appl. 1984, 35, 217-220.

(11) Nufio, C. R.; Papaj, D. R. Host marking behavior in phytophagous insects and parasitoids. Entomol. Exp. Appl. 2001, 99, 273-293.

(12) Aluja, M.; Díaz-Fleischer, F. Foraging behavior of Anastrepha ludens, A. obliqua, and A. serpentina in response to feces extracts containing host marking pheromone. I. Chem. Ecol. 2006, 32, 367389.

(13) Boller, E. F.; Aluja, M. Oviposition deterring pheromone in Rhagoletis cerasi L. I. Appl. Entomol. 1992, 113, 113-119.

(14) Hurter, J.; Boller, E. F.; Städler, E.; Blattmann, B.; Buser, H.-R.; Bosshard, N. U.; Damm, L.; Kozlowski, M. W.; Schöni, R.; Raschdorf, F.; Dahinden, R.; Schlumpf, E.; Fritz, H.; Richter, J.; Schreiber, J. Oviposition-deterring pheromone in Rhagoletis cerasi L.: Purification and determination of the chemical constitution. Experientia 1987, 43, 157-164.

(15) Aluja, M.; Diaz-Fleisher, F.; Edmundus, A. F.; Hagmann, L. Isolation, structural determination, synthesis, biological activity, and application as control agent of the host marking pheromone (and derivatives thereof) of fruit flies of the type Anasterpha (Diptera: Tephritidae). U.S. Patent 6,555,120 B1, 2003.

(16) Prokopy, R. J.; Averill, A. L.; Bardinelli, C. M.; Bowdan, E. S.; Cooley, S. S.; Crnjar, R. M.; Dundulis, E. A.; Roitberg, C. A.; Spatcher, P. J.; Tumlinson, J. H.; Weeks, B. L. Site of production of an oviposition-deterring pheromone component in Rhagoletis pomonella flies. I. Insect Phvsiol. 1982, 28, 1-10.

(17) Roitberg, B. D.; Lalonde, R. G. Host Marking Enhances Parasitism Risk for a Fruit-Infesting Fly Rhagoletis basiola. Oikos 1991, 61, 389-393.

(18) Aluja, M.; Boller, E. F. Host marking pheromone of Rhagoletis cerasi: field deployment of synthetic pheromone as a novel cherry fruit fly management strategy. Entomol. Exp. Appl. 1992, 65, 141-147.

(19) Edmunds, A. J. F.; Aluja, M.; Diaz-Fleischer, F.; Patrian, B.; Hagmann, L. Host marking pheromone (HMP) in the Mexican fruit fly Anastrepha ludens. Chimia 2010, 64, 37-42.

(20) Arredondo, J.; Díaz-Fleischer, F. Oviposition deterrents for the Mediterranean fruit fly, Ceratitis capitata (Diptera: Tephritidae) from fly faeces extracts. Bull. Entomol. Res. 2006, 96, 35-42.

(21) Copeland, R. S.; Wharton, R. A. Year-round production of pest Ceratitis species (Diptera: Tephritidae) in fruit of the invasive species Solanum mauritianum in Kenya. Ann. Entomol. Soc. Am. 2006, 99, 530535.

(22) Kriticos, D. J.; Stephens, A. E. A.; Leriche, A. Effect of climate change on oriental fruit fly in New Zealand and the pacific. New Zeal. Plant Prot. 2007, 60, 271-278.

(23) Steck, G. J. Mango Fruit Fly, Ceratitis cosyra (Walker) (Insecta: Diptera: Tephritidae); IFAS Extension, 2012; pp 1-3.

(24) Marc, D. M.; Copeland, R. S.; Lux, S. A.; Mansell, M.; Quilici, S.; Wharton, R.; White, I. M.; Zenz, N. Annotated check list of host plants for Afrotropical fruit flies (Diptera: Tephritidae) of the genus Ceratitis. Documentation Zoologique, Musée Royal de l'Afrique Centrale; Royal Museum for Central Africa: Tervuren, Belgium, 2002; pp 271-91.

(25) Ekesi, S.; Nderitu, P. W.; Rwomushana, I. Field infestation, life history and demographic parameters of the fruit fly Bactrocera invadens (Diptera: Tephritidae) in Africa. Bull. Entomol. Res. 2006, 96, 379386.

(26) Griesbach, J. Description of mango cultivars in Mango growing in Kenya. In World Agroforestry Centre (ICRAF); Nyamu, A. M., Simons, T., Eds.; Kul Graphics: Nairobi, Kenya, 2003; pp 18-78.

(27) Ferreres, F.; Silva, B. M.; Andrade, P. B.; Seabra, R. M.; Ferreira, M. A. Approach to the study of C-glycosyl flavones by ion trap HPLC-
PAD-ESI/MS/MS: application to seeds of quince (Cydonia oblonga). Phvtochem. Anal. 2003, 14, 352-359.

(28) Teal, P. E. A.; Gomez-simuta, Y. Juvenile hormone: Action in regulation of sexual maturity in Caribbean fruit flies and potential use in improving efficacy of sterile insect control technique for tephritid fruit flies. IOBC wprs Bull. 2002, 25, 1-15.

(29) R Development Core Team. A Language and Environment for Statistical Computing; R Foundation for Statistical Computing: Vienna, Austria, 2012.

(30) Sielezniew, M.; Stankiewicz-Fiedurek, A. M. Behavioural evidence for a putative oviposition-deterring pheromone in the butterfly, Phengaris (Maculinea) teleius (Lepidoptera: Lycaenidae). Eur. I. Entomol. 2013, 110, 71-80.

(31) Addesso, K. M.; McAuslane, H. J.; Stansly, P. A.; Schuster, D. J. Host-marking by female pepper weevils, Anthonomus eugenii. Entomol. Exp. Appl. 2007, 125, 269-276.

(32) Rosi, M. C.; Isidoro, N.; Colazza, S.; Bin, F. Source of the host marking pheromone in the egg parasitoid Trissolcus basalis (Hymenoptera: Scelionidae). I. Insect Physiol. 2001, 47, 989-995.

(33) Schoonhoven, L. M. Host-marking pheromones in lepidoptera, with special reference to two Pieris spp. I. Chem. Ecol. 1990, 16, 30433052.

(34) Teal, P. E. A.; Gomez-Simuta, Y.; Proveaux, A. T. Mating experience and juvenile hormone enhance sexual signaling and mating in male Caribbean fruit flies. Proc. Natl. Acad. Sci.U. S. A. 2000, 97, 3708-3712.

(35) Diamantidis, A. D.; Papadopoulos, N. T.; Carey, J. R. Medfly populations differ in diel and age patterns of sexual signalling. Entomol. Exp. Appl. 2008, 128, 389-397.

(36) Ferguson, A. W.; Solinas, M.; Ziesmann, J.; Isidoro, N.; Williams, I. H.; Scubla, P.; Mudd, A.; Clark, S. J.; Wadhams, L. J. Identification of the gland secreting oviposition-deterring pheromone in the cabbage seed weevil, Ceutorhynchus assimilis, and the mechanism of pheromone deposition. I. Insect Phvsiol. 1999, 45, 687-699.

(37) Quilici, S.; Schmitt, C.; Vidal, J.; Franck, A.; Deguine, J. P. Adult diet and exposure to semiochemicals influence male mating success in Ceratitis rosa (Diptera: Tephritidae). I. Appl. Entomol. 2013, 137, 142153.

(38) Flath, R. A.; Jang, E. B.; Light, D. M.; Mon, T. R.; Carvalho, L.; Binder, R. G.; John, J. O. Volatile Pheromonal Emissions from the Male Mediterranean Fruit Fly: Effects of Fly Age and Time of Day. I. Agric. Food Chem. 1993, 41, 830-837.

(39) Alfaro, C.; Vacas, S.; Zarzo, M.; Navarro-Llopis, V.; Primo, J. Solid phase microextraction of volatile emissions of ceratitis capitata (Wiedemann) (Diptera: Tephritidae): Influence of fly sex, age, and mating status. I. Arric. Food Chem. 2011, 59, 298-306.

(40) Aluja, M.; Boller, E. F. Host marking pheromone of Rhagoletis cerasi: Foraging behavior in response to synthetic pheromonal isomers. I. Chem. Ecol. 1992, 18, 1299-1311.

(41) Ramanathan, R.; Cao, K.; Cavalieri, E.; Gross, M. L. Mass spectrometric methods for distinguishing structural isomers of glutathione conjugates of estrone and estradiol. I. Am. Soc. Mass Spectrom. 1998, 9, 612-619.

(42) Depetris-Chauvin, A.; Galagovsky, D.; Grosjean, Y. Chemicals and chemoreceptors: ecologically relevant signals driving behavior in Drosophila. Front. Ecol. Evol. 2015, 3, 1-21.

(43) Noctor, G.; Queval, G.; Mhamdi, A.; Chaouch, S.; Foyer, C. H. Glutathione. Arabidopsis Book 2011, 9, e0142.

(44) Meister, A.; Anderson, M. E. Glutathione. Annu. Rev. Biochem. 1983, 52, 711-760.

(45) Rennenberg, H. Glutathione metabolism and possible biological roles in higher plants. Phytochemistry 1980, 21, 2771-2781.

(46) Alscher, R. G. Biosynthesis and antioxidant function of glutathione in plants. Physiol. Plant. 1989, 77, 457-464.

(47) Ketterer, B. Protective role of glutathione and glutathione transferases in mutagenesis and carcinogenesis. Mutat. Res. Fundam. Mol. Mech. Mutagen. 1988, 202, 343-361.

(48) Zeeck, E.; Müller, C. T.; Beckmann, M.; Hardege, J. D.; Papke, U.; Sinnwell, V.; Schroeder, F. C.; Francke, W. Cysteine-glutathione 
disulfide, the sperm-release pheromone of the marine polychaete

Nereis succinea (Annelida: Polychaeta). Chemoecology 1998, 8, 33-38.

(49) Ranson, H.; Hemingway, J. Mosquito glutathione transferases.

Methods Enzvmol. 2005, 401, 226-241.

(50) Simon, J. Y. Insect glutathione S-transferases. Zool. Stud. 1996,

$35,9-19$. 


\section{SUPPLEMENTAL INFORMATION}

Identification of the Ubiquitous Antioxidant Tripeptide Glutathione as a Fruit Fly Semiochemical

Xavier Cheseto, ${ }^{\dagger},{ }^{\ddagger}$ Donald L. Kachigamba, ${ }^{\S}$ Sunday Ekesi, ${ }^{\dagger}$ Mary Ndung’u, ${ }^{\ddagger}$ Peter E. A. Teal, ${ }^{,}, \#$ John J. Beck,,$\stackrel{\perp}{ }$ and Baldwyn Torto* ${ }^{* \dagger}$

Supplemental Table S1: Median total discrimination time and range taken by C. cosyra against oviposition substrates treated with (A) aqueous solution of $C$. cosyra female fecal matter and a control (distilled water), (B) aqueous solution of C. cosyra female specific compound and a control (distilled water)

\begin{tabular}{|c|c|c|c|c|c|c|c|}
\hline & \multirow[b]{2}{*}{$\begin{array}{l}\text { Dose } \\
(\mathrm{mg} / \mathrm{ml})\end{array}$} & \multirow[b]{2}{*}{$\begin{array}{l}\text { Respondent } \\
\text { species }\end{array}$} & \multirow[b]{2}{*}{$\mathrm{n}$} & \multicolumn{2}{|l|}{ Treatment } & \multicolumn{2}{|l|}{ Control } \\
\hline & & & & $\begin{array}{l}\text { Median } \\
\text { total } \\
\text { oviposition } \\
\text { time (min) }\end{array}$ & $\begin{array}{l}\text { Range } \\
(\min )\end{array}$ & $\begin{array}{l}\text { Median } \\
\text { Total } \\
\text { oviposition } \\
\text { time (min) }\end{array}$ & $\begin{array}{l}\text { Range } \\
(\min )\end{array}$ \\
\hline A & 10 & C. cosyra & 100 & 18.7 & $10.0-27.0$ & 5.3 & $1.6-13.5$ \\
\hline B & $\begin{array}{l}1 \\
5 \\
10\end{array}$ & $\begin{array}{l}\text { C. cosyra } \\
\text { C. cosyra } \\
\text { C. cosyra }\end{array}$ & $\begin{array}{l}100 \\
100 \\
100\end{array}$ & $\begin{array}{l}7.2 \\
13.1 \\
10.1\end{array}$ & $\begin{array}{l}3.9-13.3 \\
8.3-17.0 \\
7.1-25.1\end{array}$ & $\begin{array}{l}6.5 \\
3.9 \\
5.2\end{array}$ & $\begin{array}{l}3.6-15.6 \\
2.0-7.0 \\
2.7-8.4\end{array}$ \\
\hline
\end{tabular}


Supplemental Table S2: Median total discrimination time and range taken by $C$.

cosyra, C. fasciventris C. rosa, C. capitata and B. cucurbitae against oviposition substrates treated with aqueous solution of GSH and a control (distilled water)

\begin{tabular}{|c|c|c|c|c|c|c|}
\hline \multirow{2}{*}{$\begin{array}{l}\text { Dose } \\
(\mathrm{mg} / \mathrm{ml})\end{array}$} & \multirow[b]{2}{*}{$\begin{array}{l}\text { Respondent } \\
\text { species }\end{array}$} & \multirow[b]{2}{*}{$\mathrm{n}$} & \multicolumn{2}{|c|}{ Treatment } & \multicolumn{2}{|c|}{ Control } \\
\hline & & & $\begin{array}{c}\text { Median } \\
\text { total } \\
\text { oviposition } \\
\text { time (min) }\end{array}$ & $\begin{array}{l}\text { Range } \\
\text { (min) }\end{array}$ & $\begin{array}{c}\text { Median } \\
\text { total } \\
\text { oviposition } \\
\text { time (min) }\end{array}$ & $\begin{array}{l}\text { Range time } \\
\text { (min) }\end{array}$ \\
\hline 1 & C.cosyra & 100 & 14.0 & $4.0-29.3$ & 10.3 & $3.0-29.5$ \\
\hline 1 & C. fasciventris & 100 & 12.3 & $5.1-29.3$ & 10.5 & $2.5-29.2$ \\
\hline 1 & C. rosa & 100 & 12.4 & $3.4-29.4$ & 10.5 & $1.6-29.6$ \\
\hline 1 & C. capitata & 100 & 10.4 & $1.3-20.0$ & 9.4 & $3.9-25.6$ \\
\hline 1 & B. cucurbitae & 100 & 11.3 & $2.2-23.5$ & 6.8 & $3.7-24.9$ \\
\hline 5 & C.cosyra & 100 & 13.6 & $6.0-29.2$ & 17.1 & $2.0-29.3$ \\
\hline 5 & C. fasciventris & 100 & 13.5 & $4.0-29.1$ & 14.1 & $2.4-29.5$ \\
\hline 5 & C. rosa & 100 & 13.8 & $4.0-24.0$ & 13.9 & $2.4-29.5$ \\
\hline 5 & C. capitate & 100 & 14.7 & $5.2-25.6$ & 12.5 & $2.6-29.6$ \\
\hline 5 & B. cucurbitae & 100 & 9.3 & $4.3-27.8$ & 10.3 & $4.7-23.6$ \\
\hline 10 & C.cosyra & 100 & 16.0 & $3.0-28.8$ & 7.0 & $2.0-16.6$ \\
\hline 10 & C. fasciventris & 100 & 19.4 & $4.2-29.1$ & 9.9 & $3.0-19.2$ \\
\hline 10 & C. rosa & 100 & 16.1 & $3.1-28.6$ & 10.3 & $3.0-18.5$ \\
\hline 10 & C. capitate & 100 & 17.4 & $3.3-29.4$ & 10.5 & $1.6-17.2$ \\
\hline 10 & B. curcubitae & 100 & 15.3 & $4.5-23.9$ & 12.7 & $4.7-15.1$ \\
\hline
\end{tabular}


Supplemental Figure S1. Representative overlaid total ion chromatography [for C.cosyra males (blue) C. cosyra females (red), Solvent blank (green) and yeast hydrolysate (pink)] showing C. cosyra FSC (circled at rt $4.5 \mathrm{~min}$ )

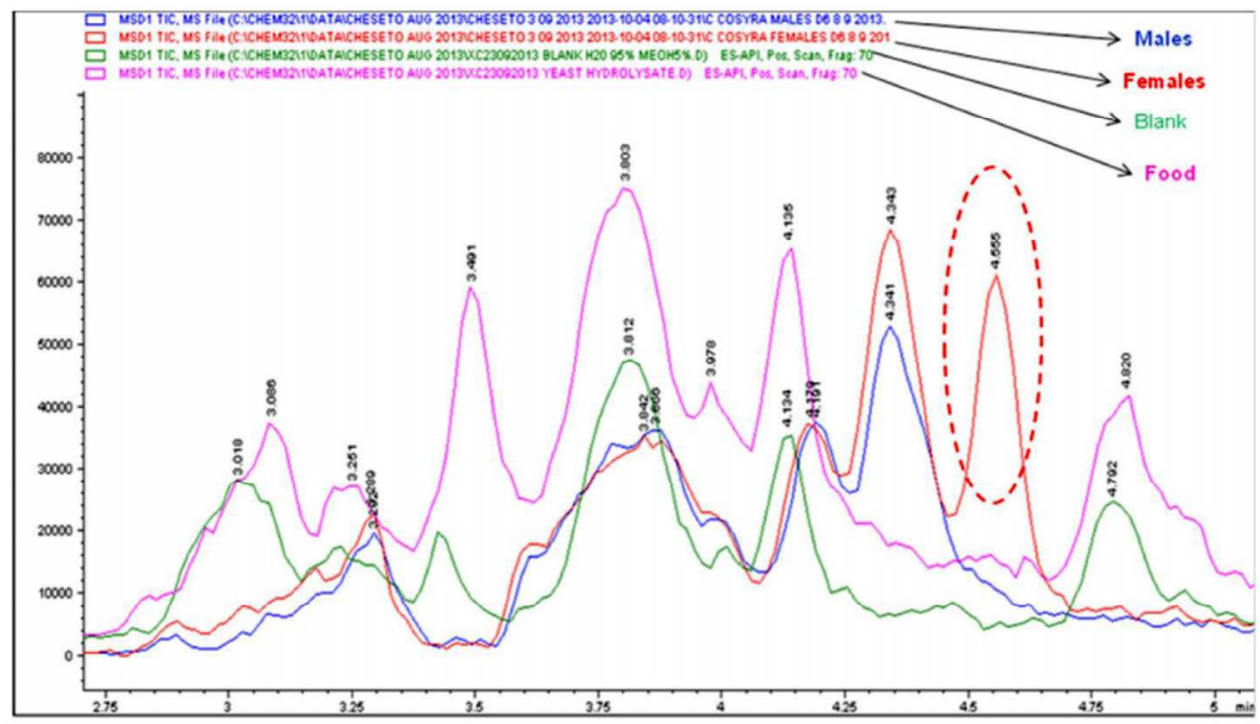


Supplemental Figure S2. Representative mass spectrum showing (1a) natural GSH, (1b) synthetic GSH, (2) glycine, (3) cysteine and (4) glutamic acid
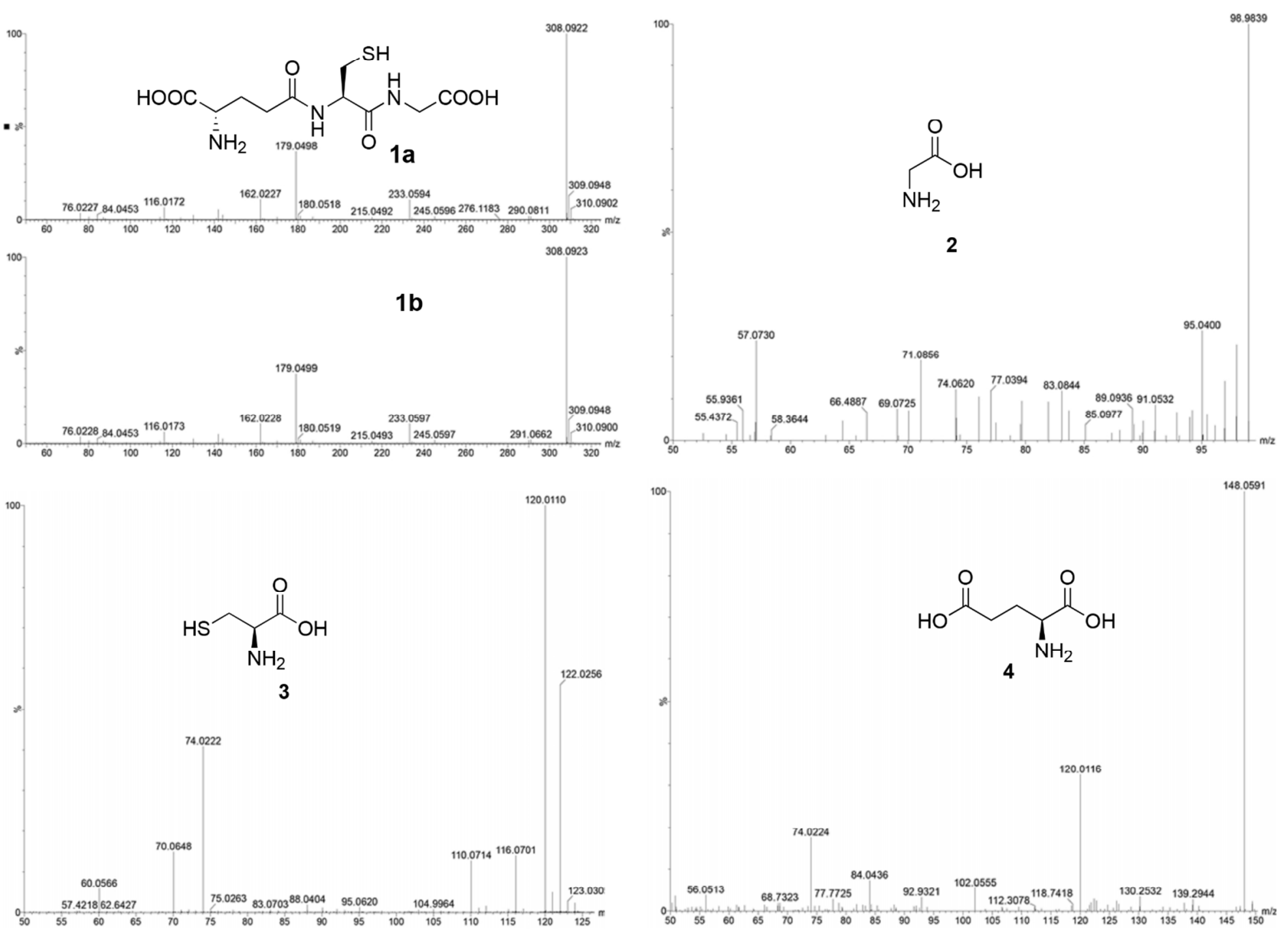